\title{
Nest predation by raccoon dog Nyctereutes procyonoides in the archipelago of northern Sweden
}

\author{
Fredrik Dahl (iD) Per-Arne Åhlén
}

Received: 30 April 2018/Accepted: 9 October 2018/Published online: 15 October 2018

(C) The Author(s) 2018

\begin{abstract}
The raccoon dog is a medium sized canid native to East-Asia. It was introduced to the western Soviet Union during the first half of the twentieth century, and has since then spread to, and established in, many European countries where it now is considered invasive. Raccoon dogs are suspected to have negative impacts on biodiversity, for example through nest predation, but empirical evidence is scarce. In this study we used GPS monitoring combined with camera traps on both artificial and natural nests to find out: (1) if raccoon dogs find and scavenge eggs from artificial nests, (2) if the scavenging from raccoon dogs is additive or compensatory to the scavenging from native species, and, (3) if raccoon dogs actively scare brooding birds off their nests and prey on their eggs. We found that raccoon dogs effectively located artificial nests and scavenged their eggs. There was a significantly higher scavenging frequency on experiment islands with both raccoon dogs and native scavengers, than on control islands with only native scavengers. There was no difference in native
\end{abstract}

F. Dahl (两)

Swedish University of Agricultural Sciences, Department of Ecology, Grimsö Wildlife Research Station,

SE-730 91 Riddarhyttan, Sweden

e-mail: fredrik.dahl@slu.se;

fredrik.dahl@jagareforbundet.se

F. Dahl · P.-A. Åhlén

Swedish Association for Hunting and Wildlife

Management, Öster Malma, 61191 Nyköping, Sweden scavenging frequency on islands with versus without a raccoon dog, suggesting an additive effect from the raccoon dog on top of the native scavenging. GPStracked raccoon dogs moved intensively in the archipelago during the bird breeding season, swimming long distances to reach new islands if needed. Raccoon dogs that arrived on islands with natural nests actively scared brooding hens, up to the size of graylag goose, off their nests and preyed on their eggs. Raccoon dogs preyed on all the eggs they found, but discarded the egg shells. Not consuming the egg shells consequently leads to few visible traces of eggs in their stomachs or faeces, which in turn may explain why egg predation by raccoon dogs has been largely overlooked in previous studies. We discuss the potential impact of raccoon dogs on biodiversity, in the light of our new findings, and conclude that the raccoon dog may have a much larger effect on the breeding success of ground nesting sea birds than what has so far been the predominating view in the scientific literature.

Keywords Raccoon dog $\cdot$ Nyctereutes

procyonoides $\cdot$ Nest predation $\cdot$ Invasive $\cdot$ Archipelago

\section{Introduction}

The raccoon dog (Nyctereutes procyonoides) is classified as an invasive alien species in Europe (EC 2017). It is a medium-size canid native to East-Asia, 
that was introduced mainly to the European parts of the former Soviet Union during the first half of the twentieth century (Kauhala and Kowalczyk 2011). Since then, it has spread and established viable populations throughout Eastern Europe, the Baltic countries, Poland, Germany, and Finland, and it is now one of the most successful alien carnivores in Europe (Weidema 2000; Kauhala and Kowalczyk 2011).

The raccoon dog can reach high densities in its introduced range. In good mainland habitats, one adult pair per $\mathrm{km}^{2}$ has been calculated from home range sizes, with an average litter size of 8-10 (up to 16) pups/year (Kauhala et al. 2010; Helle and Kauhala 1995). The raccoon dog is an excellent swimmer and thrives in wetlands and archipelagos. In the $1562 \mathrm{~km}^{2}$ large Åland archipelago, in the Baltic Sea between Finland and Sweden, 3.3 raccoon dogs were killed on average per $\mathrm{km}^{2}$ in 2016 (R. Juslin, pers. comm.), and in an experiment, Väänänen et al. (2007) culled up to 20 raccoon dogs per $\mathrm{km}^{2} /$ year in rich wetlands in southern Finland. Density, as well as litter size and northern distribution, has been shown to increase with a warmer climate (Helle and Kauhala 1991; Kauhala 1992; Helle and Kauhala 1995; Kauhala and Kowalczyk 2011). About 25 years ago, the northern limit where the raccoon dog could reproduce successfully lay south of the Arctic Circle (Helle and Kauhala 1991). During the last decades the annual mean temperature has risen about $2{ }^{\circ} \mathrm{C}$ in northern Finland and Sweden (Finnish Meteorological Institute 2018, SMHI 2016). As predicted, the raccoon dog has since about a decade ago also established north of the Arctic circle and invaded northern Sweden, through the archipelago where this study is undertaken and via the main land north of the Gulf of Bothnia, where a management program has been set up to stop it from establishing in Sweden and Norway (Dahl et al. 2010; Mirdinec 2014).

Even though it is classified as an invasive alien species of EU-concern, there is still a lack of scientific consensus regarding the raccoon dogs' impact on biodiversity, and especially its role as an active predator (Kauhala and Kowalczyk 2011). The raccoon dog is a very adaptable omnivore, able to survive, disperse and reproduce effectively in new environments (Kowalczyk 2014). Raccoon dogs are suspected to have negative impacts on ground nesting birds, especially in wetlands and insular habitats during breeding time, but scientific evidence has so far been inconsistent (Kauhala and Auniola 2001; Kauhala and Kowalczyk 2011). Väänänen et al. (2007), for example, found that the breeding success of waterbirds increased when the raccoon dog population was decreased in wetlands, while Kauhala (2004) did not find evidence of a negative impact in another study. Kauhala and Kowalczyk (2011) do refer to a number of studies where birds, eggs and amphibians have been found in the diet of the raccoon dog, although, especially egg remains (shells), were typically found in very small proportions. In one study, Kauhala and Auniola (2001) found that up to $40 \%$ of investigated raccoon dog faeces, collected in the outer archipelago during spring and summer, contained egg shells. The authors, however, argued that most eggs and birds were probably found as abandoned eggs or carcasses and scavenged, and therefore not actively preyed upon (Kauhala and Auniola 2001; Kauhala and Kowalczyk 2011).

In this paper we provide data from our management project (2010-ongoing) to show that raccoon dogs move naturally between islands in the archipelago of the county of Norrbotten in northern Sweden during the bird breeding season. In addition, we designed an experiment to investigate the following questions;

1. Will raccoon dogs arriving to an island find and scavenge eggs from artificial bird nests?

2. If so, is the raccoon dog's scavenging on artificial nests additive or compensatory to the scavenging from native species?

3. Do raccoon dogs find and actively prey on natural nests protected by brooding hens?

\section{Methods}

Study area

The study took place in the archipelago of Norrbotten in northern Sweden between 2015 and 2017 (Fig. 1). The archipelago is situated $100 \mathrm{~km}$ south of the Arctic Circle in the northernmost part of the Baltic sea, and consists of a large number of islands (Fig. 1), of which 3306 islands $>20 \mathrm{~m}^{2}$ (Ankre and Nilsson 2006; Bottenvikens skärgård 2016). The water is brackish, with less than $10 \%$ of the salt content of the Atlantic. The sea freezes in January and remains frozen until March-April (Ankre and Nilsson 2006). The 


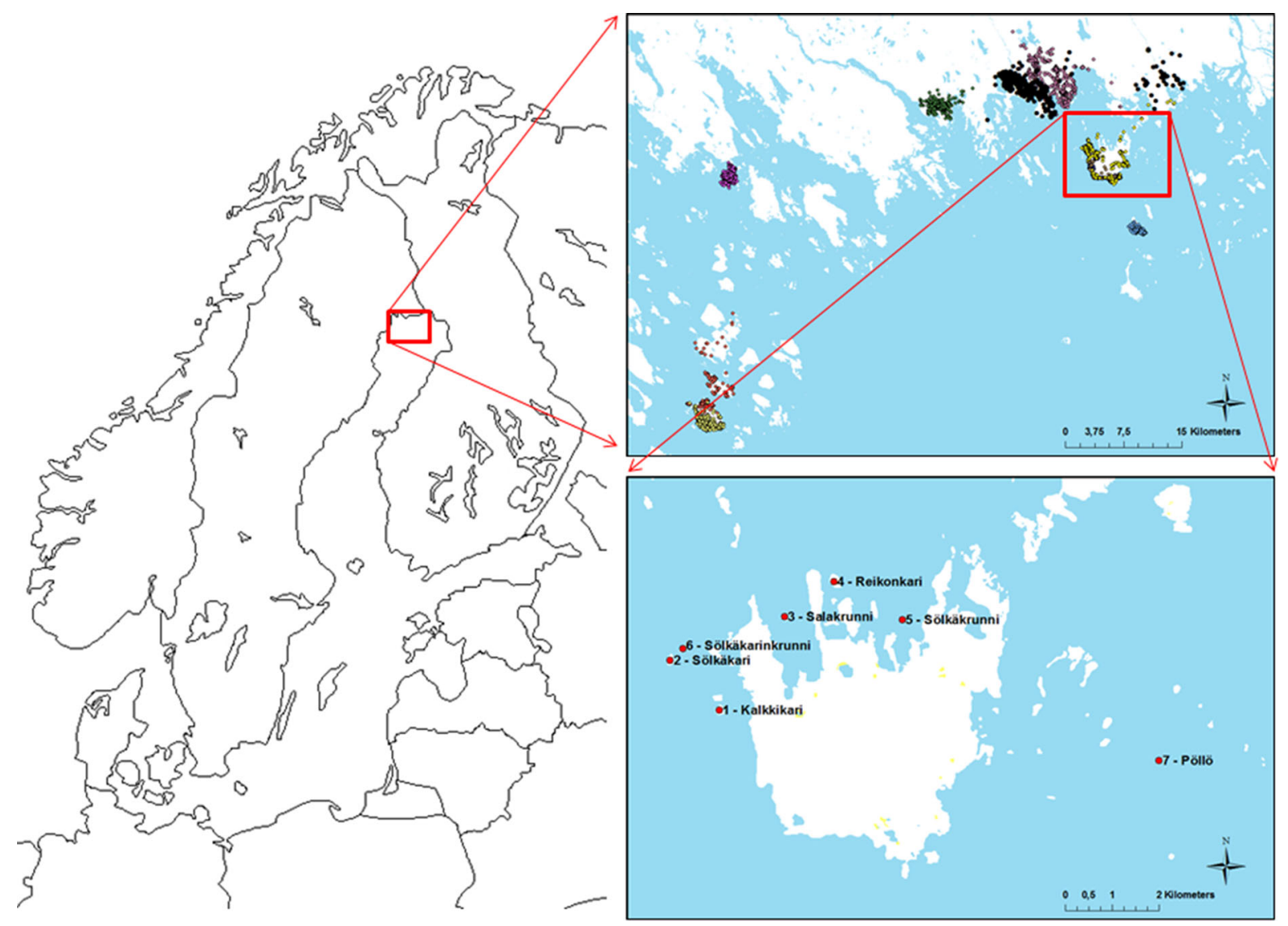

Fig. 1 Location of the study area in northern Sweden (left), the Norrbotten archipelago with positions of ten GPS collared raccoon dogs during summers 2010-2016 (upper right), and locations of study islands (lower right)

Norrbotten archipelago harbors several bird species of importance from a national perspective, constituting a large proportion of the total Swedish population of, for example, little gull (Hydrocoloeus minutus), Caspian tern (Sterna caspia), and little tern (Sternula albifrons) (Länsstyrelsen 2009). Parts of the archipelago, for example Haparanda Skärgård National Park, are protected, partly due to the unique bird fauna, which includes several threatened species (Council Directive 92/43/EEG, 79/409/EEG).

Study islands and natural fauna

Islands used in the study (Fig. 1) are between 0.13 and 4.97 ha (Table 1). The vegetation on the islands consists of shrubs (common sea-buckthorn (Hippophae rhamnoides), shrub willows (Salix Spp.), bilberry (Vaccinium myrtillus), lingonberry (V. vitisidaéa), heather (Calluna vulgaris), crowberry
(Empetrum nigrum)), and trees (Norwegian spruce (Picea abies), Scots pine (Pinus sylvestris) and birches (Betula pendula and B. pubescens)).

Birds in the area breed between May and August depending on species. Birds commonly found on the study islands include greylag goose (Anser anser), Canada goose (Branta canadensis), mallard (Anas platyrhynchos), velvet scoter (Melanitta fusca), tufted duck (Aythya fuligula), breasted merganser (Mergus serrator), common sandpiper (Actitis hypoleucos), black-headed gull (Larus ridibundus), common gull (Larus canus), European herring gull (Larus argentatus), common tern (Sterna hirundo), Eurasian magpie (Pica pica), raven (Corvus corax), and hooded crow (Corvus cornix). Mammals occasionally seen on the islands, apart from the raccoon dog, include American mink (Neovison vison), red fox (Vulpes vulpes), badger (Melis melis), otter (Lutra lutra), moose (Alces alces) and Roe deer (Capreolus capreolus). The 


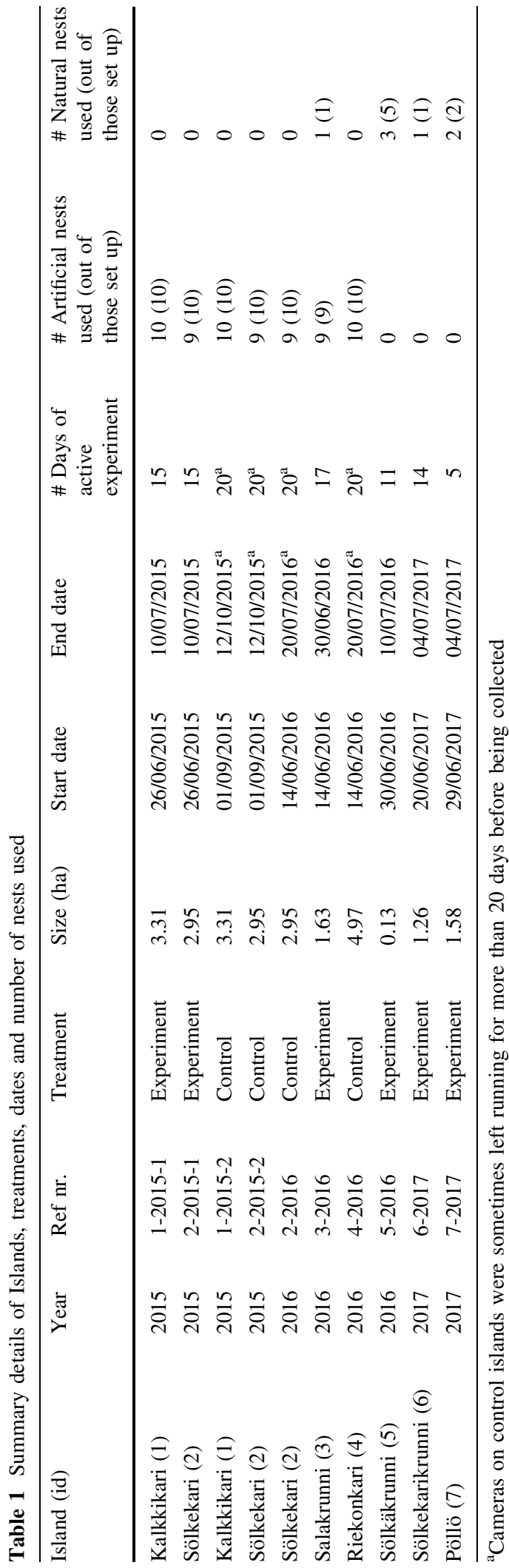

American mink is an alien and harmful predator species in Europe (Bonesi and Palazon 2007). In this study it will, however, be included in the native predator fauna when assessing the effect of the raccoon dog.

Raccoon dog data from the management project

Norrbotten County is the invasion front of the raccoon dog from Finland into Sweden (Herfindal et al. 2016). More than 140 wild raccoon dogs have been sterilized (to prevent reproduction) and collared with GPS units (Tellus Ultra Light, Followit AB) in northern Sweden from 2010 until 2018 as part of a management project (Dahl et al. 2010; MIRDINEC 2014). The main goal of the management project is to keep the population as low as possible and to stop the raccoon dog from dispersing to, and establishing in, the southern parts of Sweden and Norway (Dahl et al. 2010). One purpose of the collared animals is to use them as Judas animals to find and cull new animals (Dahl et al. 2010; MIRDINEC 2014). Another purpose is to learn more about where, when, and how the raccoon dogs move, and which types of habitats they utilize in the dispersal front, to improve management efficiency (Herfindal et al. 2016; Melis et al. 2015). To date, well over 500,000 positions have been gathered from these animals. In this paper, data from the management project, more specifically from animals residing in the archipelago of Norrbotten, provide examples of how raccoon dogs move naturally in the archipelago during summertime (May 15-Aug 15), i.e. the breeding time for ground nesting birds. The schedules of the GPStransmitters varied between animals since the data set includes animals from a six-year period, and the need for positions for management purposes varied between years, but at minimum the transmitters were set to make four positioning attempts per day. The data was automatically entered into the WRAM (wireless remote animal monitoring) database system for data validation and management (Dettki et al. 2013). As examples in this paper, we only included individuals with more than 200 positions during at least one consecutive month and used all available positions from these animals. The raccoon dogs' movements are, however, likely to have been underestimated as gaps over a couple of days sometimes occurred in the data due to poor GSM coverage. All animals included were either both captured and released at the same site 
in the archipelago, or had moved there themselves after previously being captured and released elsewhere.

\section{Nest predation study}

The nest predation study was undertaken during the summers of 2015-2017. To avoid disturbing the birds we primarily used artificial nests on islands without known breeding birds. It was, however, also necessary to use some natural nests to find out if the raccoon dog is mainly a scavenger, as has been suggested by e.g. Kauhala and Auniola (2001), or also an active predator regarding bird nests in insular habitats. We have used the terms scavenger/scavenging in relation to our unprotected artificial nests, and predator/predation when they had to actively hunt, or in this case find and scare brooding birds off their nests, to get the eggs.

In 2015 we used only artificial nests, in 2016 we used both artificial and natural nests, and in 2017 we used only natural nests. If used as a proxy for nest predation, artificial nests typically overestimate predation on natural nests because their placement, selected by humans, is inferior to the selection of the birds', and because of the absence of a bird on the nest to hide it from predators or to protect it if discovered (Willebrand and Marcstrom 1988; Zanette 2002; Jahren 2017). Artificial nests may, however, help to reveal the raccoon dog's relative efficiency in finding (and scavenging) eggs compared with native scavengers, and whether raccoon dog scavenging of artificial nests is additive or compensatory to scavenging from native scavengers. An additive effect on native scavenging is especially interesting if the raccoon dog is also revealed to be an active predator on natural nests. Artificial nests were constructed by natural material (ten nests per island) and hidden under roots, reeds or shrubs to mimic natural nest placement as far as possible. In each nest, we placed three brown domestic hen (Gallus gallus domesticus) eggs on a bed of, and covered with, down, mimicking the setting arranged by many ground nesting bird species when temporarily leaving their nests. To minimize human scent, we handled the nests and eggs with latex gloves and left the eggs outdoors for a minimum of three days prior to placing them in the field (Sieving and Willson 1998; Anderson et al. 2016). A game camera (Scout Guard 560 or Scout Guard 550M-14SHD Nordic) was set up approximately $2 \mathrm{~m}$ from the nests during the study to be able to identify the perpetrator if the eggs were scavenged. At each natural nest found, we put up cameras with MMS function (UOVision UM595), which sends pictures in real time.

Four raccoon dogs, two males and two females, were sterilized, equipped with GPS-collars (running on 1-h schedules to enable detailed tracking), and released on the experiment islands. Only one raccoon dog was released on each island. Different individuals were used on all artificial nest experiment islands. On the natural nest islands, one new individual and one of the individuals previously used on one of the artificial nest islands was used. The raccoon dogs were released from a boat about $50 \mathrm{~m}$ from the islands allow them to settle without disturbance. For the natural nests we waited at least until the birds, according to our MMScameras, were back on their nests before releasing the raccoon dog, which typically took about $2 \mathrm{~h}$. For the artificial nests, we waited at least $2 \mathrm{~h}$ after putting out nests and cameras before releasing the raccoon dog. The raccoon dogs were able to leave the islands whenever they wanted, as islands were close to other islands or the mainland (Fig. 1).

Two islands were used for the artificial nest experiment in 2015 (1-2015-1 and 2-2015-1), and as control we reset all nests after the raccoon dogs were taken away and repeated the trial without raccoon dogs (1-2015-2 and 2-2015-2) (Fig. 1, Table 1). In 2016 one experiment island (3-2016), and two control islands (2-2016 and 4-2016) were used in the artificial nest experiment (Fig. 1, Table 1). In 2016 the nests on the experiment and the control islands were put out and monitored during the same time period. Ten artificial nests were set on all experiment and control islands, although three nests had to be omitted from the analysis of the artificial nest experiment 2015-2016 due to camera failures (Table 1).

A natural nest of common sandpiper was found when the artificial nests were set in 2016 (3-2016), and was incorporated in the natural nest experiment instead (Table 1). In 2016 we also had one island (52016), with only natural nests (Fig. 1, Table 1). All of these five natural nests were of tufted duck. One of these nests was, however, scavenged by common gulls within $2 \mathrm{~h}$ of the camera being set up, before the tufted duck had returned to the nest and before the raccoon dog was released on the island. The eggs were laying in plain sight, not covered by the hen or by down due to our disturbance, making it easily visible from the air. 
For another of the tufted duck nests the camera malfunctioned. In 2017 we found two islands with natural nests, one with a nest of graylag goose (62017) and one with both a nest of breasted merganser and a nest of graylag goose (7-2017) (Fig. 1, Table 1). The latter island had more nests on it, but cameras were only placed on two to avoid disturbing the birds too much. Finding islands with breeding birds within the area where we had permission to perform the study, which was outside protected areas, proved to be difficult. As a consequence, we were not able to locate similar islands with natural nests of the same species to use as controls. In all, our results are based on 66 artificial nests and seven natural nests (Table 1).

\section{Statistical analyses}

We used the camera trap data to determine the day each nest was scavenged or, in the case of natural nests, preyed on. The rate of artificial nests scavenging on each island was calculated with Kaplan-Meier survival estimates in Excel (V. 14.0.7177.5000) (Pollock et al. 1989). Differences in scavenging frequency within and between treatments (with or without raccoon dog present) were analyzed after 20 days using a two-tailed Z-test according to Pollock et al. (1989). If no statistically significant difference was found within the same treatment, first between islands the same year and then between years, the data was pooled by treatment. A period of 20 days was used in the analysis because this corresponds to a normal brooding time for many ground nesting bird species in the area. However, two raccoon dogs left their islands before 20 days, when their cameras were also retrieved to secure the data, and for a third raccoon dog weather conditions forced us to retrieve the cameras earlier than planned. In these occasions the remaining nests were censused up to 20 days, but this did not have any significant effect on the results. Cameras on the control islands nests were out at least 20 days, but only data up to day 20 was included in the statistical analyses. One of the control islands was used both in 2015 and 2016, in effect a pseudoreplication, but the results did not change if either of the replicates were omitted. Natural nest predation is described and discussed, but no statistical analyses were made due to the low sample size. Map visualizations were made with ArcMap 10.3.1.
To investigate if raccoon dog scavenging is additive or compensatory to the scavenging from native species we have compared existing (native) scavenging of artificial nests on control islands (where only native scavengers were present), with the native scavenging on experiment islands (where a raccoon dog was also present). If the native scavenging is unchanged when adding a new source of scavenging (the raccoon dog), all raccoon dog scavenging would then be additive. If the native scavenging decreases when the raccoon dog is added, the raccoon dog scavenging would be compensatory, either partial or complete, to the native scavenging (Bartmann et al. 1992; Boyce et al. 1999; Heisey and Patterson 2006). In some circumstances adding a new source of mortality can also result in decreased overall mortality, i.e. if a new predator reduces other predators' impact and do very little harm themselves (Anderson et al. 2016).

\section{Results}

Occurrence and movement of raccoon dogs in the archipelago

In our position data of GPS-collared management raccoon dogs from 2010 to 2016 we found ten animals that had been utilizing the archipelago during spring and summer, coinciding with the breeding time of birds, that had over 200 positions $(\mathrm{N}=282-1477)$ during at least one consecutive month (Fig. 1). We have previously shown that raccoon dogs are generally associated with wetlands during spring and summer (Melis et al. 2015), but in this study we also found that raccoon dogs living mainly on the mainland, close to the sea, regularly move along the coast line including islands close to the mainland (Fig. 2a). Other raccoon dogs lived solely on islands in the outer archipelago (Figs. 1, 2b). The raccoon dogs in the outer archipelago typically moved between islands, sometimes swimming quite long distances, lingering on one island for a couple of days up to several weeks, before moving on to the next one (Fig. 2b). The size of visited islands varied from tens of $\mathrm{m}^{2}$ and upwards. The longest swimming distance registered was $1.2 \mathrm{~km}$. Although they are excellent swimmers, raccoon dogs found on islands or groups of islands far out in the archipelago in summer, may also have walked there over the ice during winter. 

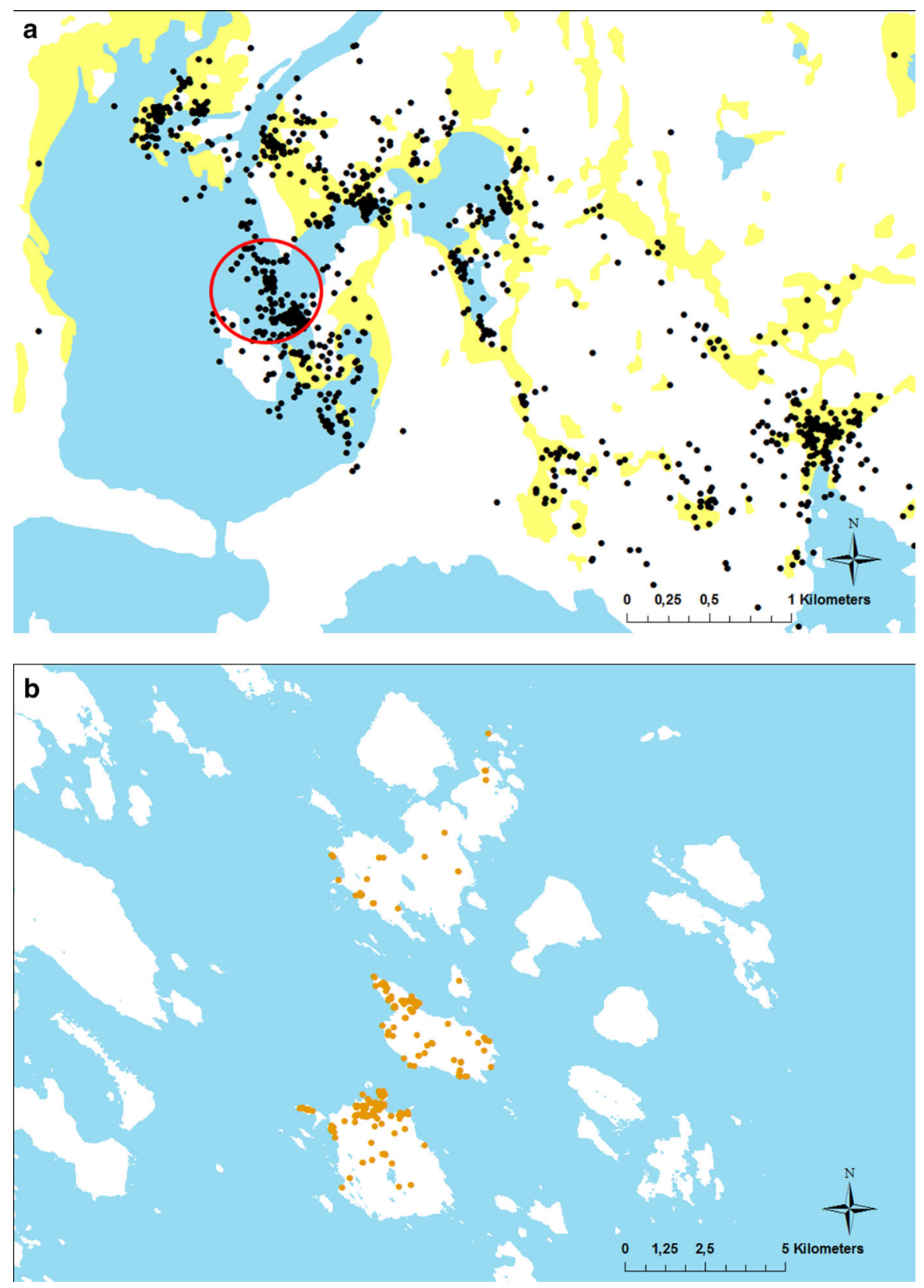

Fig. 2 Two GPS tagged raccoon dogs moving in the archipelago during the breeding time of ground nesting sea birds. One of the raccoon dogs (a) (May 15, 2016-Aug 15, 2016, $\mathrm{n}=1477$ ) mainly utilized coastal wetlands, but also moved along the shoreline and out on numerous islands and reed beds in the archipelago, all of which are habitats used by ground nesting sea birds during the breeding time. The habitat in the red circle, where the raccoon dog is seemingly out in open water, is a marshland with reed beds. Also note the raccoon dog's selection for wetlands (yellow areas) on the mainland (a). The other raccoon $\operatorname{dog}(\mathbf{b})$, in the outer archipelago, visited at least 9 separate islands between May 26, 2010 and Aug 14, 2010 $(\mathrm{n}=282)$ and swam long distances to do so 
Fig. 3 Nest survival (and $95 \% \mathrm{CI}$ ) on islands where both native predators (black solid line, Surv = 0.964) and a raccoon dog (black dashed line, Surv 0.051) were present simultaneously with one group at a time censused $(\mathrm{N}$ nests $=28)$, and on islands where only native predators were present (red solid line, Surv $=0.949, \mathrm{~N}$ nests $=39$ )

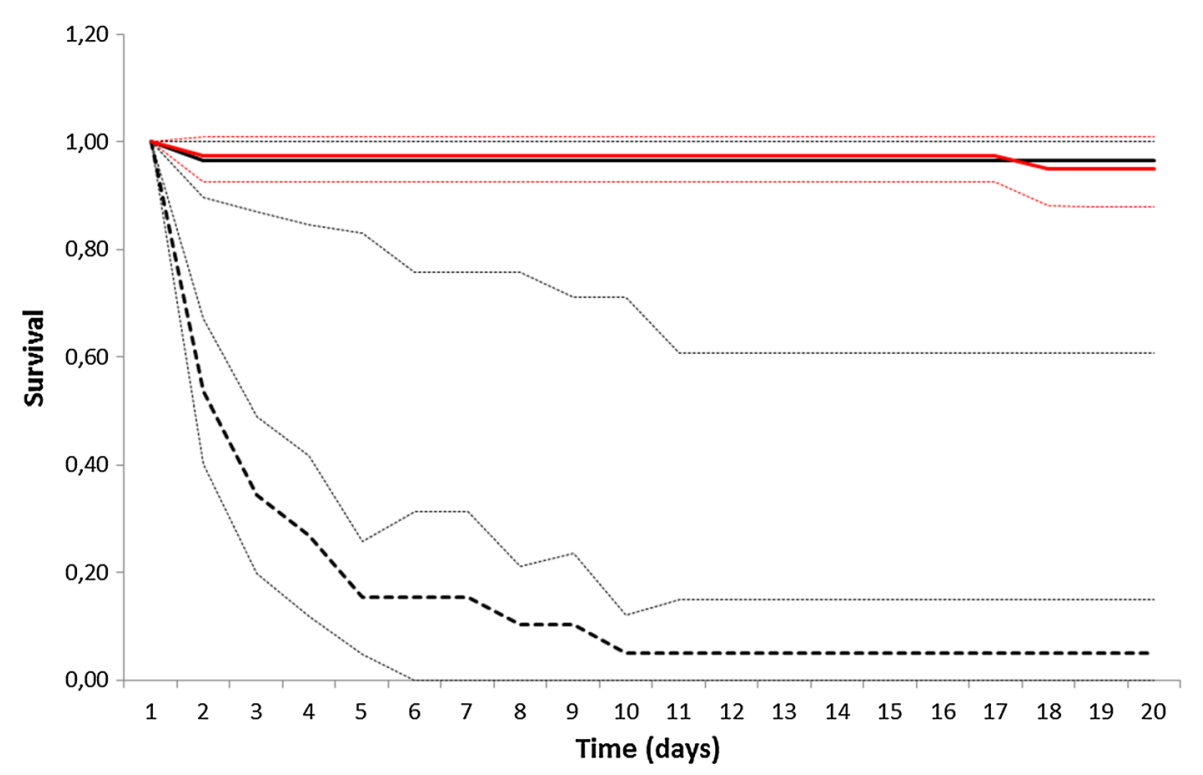

Scavenging of artificial nests

Scavenging of artificial nests was much higher on experiment islands with a raccoon dog present than on control islands with only native scavengers present (Fig. 3). Results were statistically significant both when analyzed within years (2015; $Z=14.26$, $P<0.01,2016 ; \mathrm{Z}=18.49, P<0.001)$ and when years were pooled $(\mathrm{Z}=18.08, P<0.001)$. All but one out of 28 nests were scavenged within nine days on islands with a raccoon dog present. In 25 out of 27 cases, raccoon dog was the perpetrator. One nest was scavenged by a hooded crow (day one), and in another case it was not possible to determine if the raccoon dog or a crow was the first to scavenge the nest (day four). On the control islands, only two out of 38 nests were scavenged within 20 days, by a raven on day six and by a crow after 19 days.

Scavenging by native scavengers on islands with a raccoon dog present (raccoon dog scavenging censused) versus not present were almost identical ( $\mathrm{Z}=0.09, \quad P=0.93$, Fig. 3 ). When raccoon $\operatorname{dog}$ scavenging was added (uncensused) on the experiment islands, the proportion of nests not scavenged after 20 days decreased drastically, from 96.4 to $4.8 \%$, which was statistically significant $(Z=4.83$, $P=0.001)$. The presence of a raccoon $\operatorname{dog}$ on the islands added $91.6 \%$ scavenging on top of the $3.6 \%$ scavenging from native scavengers (Fig. 3).
Movements and behavior of raccoon dogs on islands with artificial nests

The raccoon dogs moved intensively over the experiment islands during the study. On average, the raccoon dogs moved 1645, 1150 and $720 \mathrm{~m} /$ day respectively during their stay on the islands (distances based on accumulated $1 \mathrm{~h}$ positions), implying that they moved enough to at least traverse their respective islands eight, six and five times every day for as long as they stayed on their islands. Twenty-six out of 27 scavenged nests were revisited by the raccoon dogs, usually many times after they were first found $(\min =1$, median $=5, \max =28)$.

The raccoon dogs were free to leave the islands whenever they wanted. It was only some hundred meters to the closest other island or to the large island Seskarö, connected to the mainland (Fig. 1). In two out of three cases, our raccoon dogs left the experiment islands before we planned to move them, after 7 and 9 days respectively. They left their islands after all but one nest was scavenged, and all but one scavenged nest had been revisited at least once.

Nest predation, movements and behavior of raccoon dogs on islands with natural nests

As for the artificial nest islands, the raccoon dogs moved intensively on the natural nest islands. In 2016, the natural nest on 3-2016-2 (common sandpiper) was 

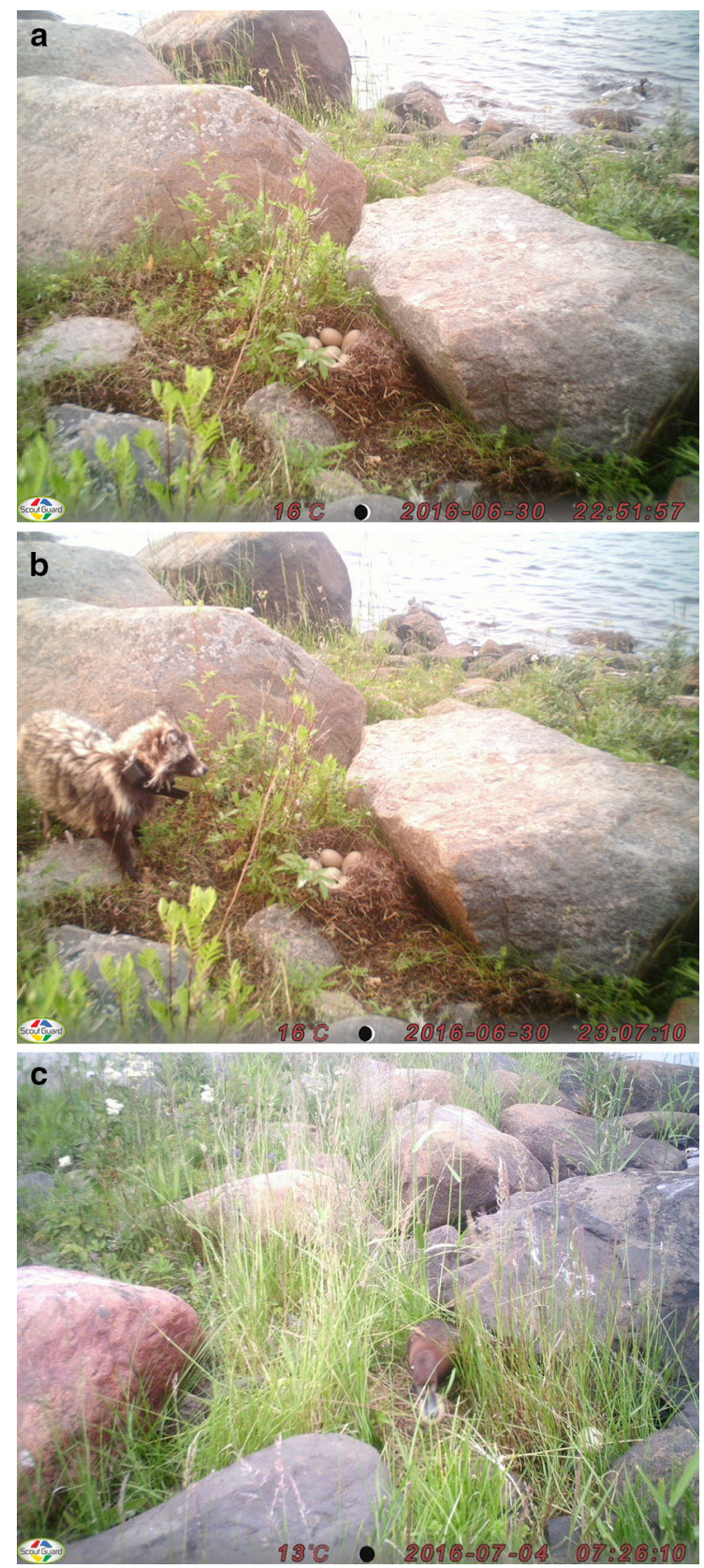

Fig. 4 Tufted duck leaving the nest (bird swimming away in the water) (a), raccoon dog captured by camera shortly after the bird left the nest (b), tufted duck disposing empty egg shells from (a different) nest, note the egg to the right with a hole in it (c)

found and preyed on by the raccoon dog after 6 days, where after the raccoon dog revisited the nest six times the following 11 days until we removed it. On the island with nests of tufted duck (5-2016), the three nests with brooding birds and functioning cameras were found and preyed on by the raccoon dog, after 4:38 $\mathrm{h}$, after 5:07 $\mathrm{h}$ and after 4 days and 6:45 $\mathrm{h}$. The brooding birds left their nests shortly before the raccoon dog was captured by the cameras (Fig. 4a, b). Two of the three birds returned to their nests and resumed brooding on remaining eggs when the raccoon dog had left. One of them returned and resumed brooding after two consecutive predation events before giving up, and the other one returned and resumed brooding once. The birds picked out shells from preyed eggs before laying down (Fig. 4c). The raccoon dog only took one or a few eggs at each visit. Eggs were eaten in or close to the nests, and the shells left behind, often just opened with a hole to be licked out (Fig. 4c). This routine was the same for the artificial nests, while e.g. ravens always took the whole egg and flew away. It took the raccoon $\operatorname{dog}$ 8:02 $\mathrm{h}$ and 24:59 h, respectively, to empty two of the nests to the last egg after first finding them. We were unable to judge the time for the third nest because the eggs were difficult to see. The raccoon dog kept returning to the nests even after they were empty, three and seven times, respectively. The nest we could not judge as empty was revisited four times after the initial visit. The raccoon dog also revisited the nest scavenged by common gulls six times in total. As was the case with two of the raccoon dogs on islands with artificial nests, this raccoon dog also left the island once all nests were emptied and revisited several times; on day nine after release, 5 days after the last nest was found and most likely 4 days after the last nest was empty.

In 2017 we had one island (6-2017) with one nest of graylag goose. It took the raccoon dog about $8 \mathrm{~h}$ from arriving to the island before visiting the nest. The goose left the nest minutes before the raccoon dog came into camera view and started praying on the nest. The goose returned after the raccoon dog had left, but only stayed for a short while and did not return again. The raccoon dog returned twice after the first visit, after five, and then $25 \mathrm{~h}$. By the last visit, a crow had also visited the nest and scavenged what was left of the eggs. Three days and $3 \mathrm{~h}$ after arrival the raccoon $\mathrm{dog}$ swam to a nearby island. It then frequented both islands for 14 days until removed by us. On the other island (7-2017), it took the raccoon dog $27 \mathrm{~h}$ to find the nest of the breasted merganser. The bird left immediately. The raccoon dog stayed for at least 20 min preying on the nest. The bird returned after 
$2 \mathrm{~h}$, picked out empty shells and then left, never to return. A common gull visited the nest 2 days after the raccoon dog. The graylag goose on the other nest left it $4 \mathrm{~h}$ after coming back from our disturbance. No predator came to the nest and the eggs were still untouched when we retrieved the raccoon dog. The raccoon dog did not leave the island before being removed by us after 5 days.

\section{Discussion}

Non-native species are recognized as one of the main threats to global biodiversity (Weidema 2000; Mack et al. 2000, McNeely et al. 2001). While most nonnative species fail to establish at all, some succeed and also become invasive in their new environment (e.g. Pejchar and Mooney 2009; Ehrenfeld 2011). Among the non-native animals, invasive mammalian predators have the largest impact on native animals, particularly in insular environments (Ebenhard 1988; Nogales et al. 2013; Doherty et al. 2016).

In this study we have shown that the raccoon dog eats eggs and that they, in addition, not only are scavengers but also active predators on bird nests. Gulls or corvids did not prey on any nests with brooding birds, indicating that the camouflage and protection a natural nest provides is well adapted for at least some native predators. Similar observations have also been made regarding nest predation on capercaillie (Tetrao urogallus) and black grouse (Lyrurus tetrix) in the boreal forest (Jahren 2017). In contrast, the raccoon dogs in our study did not hesitate to scare brooding birds, as large as graylag goose, off their nests and prey on their eggs.

Several previous studies have shown that the raccoon dog eats eggs, but usually only as a minor proportion of their diet based on the contents of egg shells in their stomachs or faeces (Sutor et al. 2010 and references therein; Kauhala and Kowalczyk 2011; Elmeros et al. 2018). It seems very unlikely that an extreme generalist omnivore should disregard such a protein rich food source like an egg if they found one. In our study, all detected eggs were consumed, but the egg shells were left behind. About half of the eggs only had a hole in the shell, through which the raccoon dogs had licked out their contents (Fig. 4c). The rest of the egg shells lay separated in a few pieces. All eggs that were eaten by raccoon dogs in front of the cameras still had their shells left when the raccoon dogs were done, although small amounts of shell may have been ingested more or less by mistake. As far as we can tell also eggs eaten by the raccoon dogs outside the range of the cameras had their shells left, but subsequent visits by gulls and corvids outside the range of the cameras made it impossible to quantify this interesting observation further. If food is abundant, like during the nesting season in most archipelagos, there is no reason to eat the non-preferred parts of a prey. In our study, there was an overabundance of eggs when the raccoon dogs arrived on the islands. They ate a few eggs from one nest and then took a break, probably to digest the eaten eggs before going back for more. A raccoon dog is probably unable to eat $8-10$ large eggs at once, due to pure physical restraints. The numbers of eggs eaten at one time may be higher when they have pups to feed, which ours did not. It is also likely that an adult with cubs would carry the eggs to the den instead of eating them on site. When all the nests were empty they usually left the islands, leaving the egg shells behind. In contrast, during periods of food depletion, an extreme omnivore like the raccoon dog will eat what is available, depending on season and opportunity (Viro and Mikkola 1981; Kauhala et al. 1998; Sutor et al. 2010; Kauhala and Kowalczyk 2011), and will probably also eat egg shells to get the thin digestible shell membranes if needed. In the study by Kauhala and Auniola (2001), quite a large proportion of the collected faeces on islands in the outer archipelago contained egg shells, which was not the case on islands in the inner archipelago. On the outer islands amphibians were almost extinct, possibly due to previous raccoon dog predation according to the authors, a disease had struck the eider (Somateria mollissima) population, and the authors suggest that raccoon dogs therefore scavenged carcasses and egg remains from dead birds on these islands. Our results suggest that only occasionally finding small amounts of egg shells in raccoon dog faeces or stomachs, cannot be interpreted as proof that raccoon dogs only rarely eat eggs. As also suggested by Sutor et al. (2010), and in the light of our new findings, we suspect that eggs in the diet of raccoon dogs are likely underestimated in most scientific studies up to date, since the egg shells, which they discard, is the only visible proof of egg consumption that can be found with traditional methods. 
Our raccoon dogs moved intensively over the experiment islands during the study, probably in search of food. Raccoon dogs revisited previously discovered nests until they were with certainty empty, including the nests initially scavenged by gulls and corvids. It is possible they did so from experience, i.e. that they had previously learnt that new eggs may appear in empty nests. They probably eventually left the islands due to food depletion, as by then several days had usually past since the last nest was empty. Two raccoon dogs did, however, not leave their islands, possibly because the alternative food on the islands was not yet depleted even though most camera nests were empty. Some support for this can be found on one of the islands (7-2017), where the raccoon dog preyed on the nest of the breasted merganser, but not the nest of the graylag goose, even though it had left the nest. When retrieving the raccoon dog, we observed a lot of preyed eggs around nests without camera surveillance. It is likely the raccoon dog never got around to scavenge the goose eggs because food was plentiful on the island, at least until we retrieved it after 5 days. The abundance of food on this island, compared with our other islands where there were usually only a few nests or only the artificial nests we laid out, may also explain why the raccoon dog only visited the breasted merganser nest once. Apart from possible undetected natural nests, there may well have been amphibians or other food sources on the islands they did not leave. It seems likely though that these two raccoon dogs would also have left the islands once the food became scarce if we had not moved them. They were certainly able to do so if they had wanted to since the distance to the closest neighboring islands were far shorter than the $1.2 \mathrm{~km}$ one of our management animals swam.

Our management data further show that raccoon dogs move intensively in wetlands, along the shorelines, and traverse between islands in the outer archipelago, including visiting small treeless islands, during the breeding time of both ground nesting sea birds and amphibians (Fig. 2a, b). We agree with Kauhala and Auniola (2001), that a raccoon dog cannot live solely on a small treeless island in the outer archipelago. They need a larger island or several islands as a base. But they do regularly visit also very small islands and reed banks, sometimes swimming long distances to do so. We can see no reason why they should not prey on nests they find during their explorations, they are after all opportunistic omnivores (Kowalczyk 2014). We even find it likely that raccoon dogs actively search for nests during such explorations because birds often nest in these habitats. Our raccoon dogs did not have partners, which does affect the size of their activity areas (Herfindal et al. 2016). Pairs utilize smaller areas, although this, if anything, should intensify their search for food even more within that area.

Our study further shows that raccoon dog scavenging on artificial nests is additive to scavenging from native species. The impact from native scavengers did not change when there was a raccoon dog on the island, compared with the control islands without raccoon dog. The total scavenging, however, increased significantly on islands with raccoon dog. Based on these results from the artificial nests, and the fact that no native predator preyed on natural nests with a brooding hen in our study, it is also likely that nest predation from raccoon dog is additive to nest predation from native predators. The raccoon dog can thereby have a limiting effect on at least some ground nesting bird populations in the archipelago through egg, and probably also chick, predation. Invasive alien species generally have a strong impact on invaded insular ecosystems, where indigenous species often have evolved in the absence of strong competition, herbivory, parasitism, or predation. Some species, whose ecological equivalents are naturally lacking in the native ecosystem, such as the raccoon dog in our case, may further have an even greater impact and are often responsible for the impoverishment of local fauna (Courchamp et al. 2003; Doherty et al. 2016). The native mammalian predators red fox and badger do occasionally visit the archipelago in our study area, but mainly the coastal areas as they are not especially active swimmers. We did not observe, or obtain photos, of any foxes or badgers on our islands during the study. As a highly opportunistic omnivore with a flexible search pattern for food, the raccoon dog further fulfills all necessary criteria for causing apparent competition on islands where, for example, one rare ground nesting bird species naturally coexists with one abundant prey species (Holt 1977; DeCesare et al. 2010). Unfortunately, the situation is even more difficult and complex since the interaction of the invasive alien American mink also needs to be taken into consideration in this equation. On our study islands American mink seemed to occur at low 
density, as we only confirmed mink presence on one island (4-2016-2), when it preyed on three nests between day 34 and 36, after the trial had ended but the cameras were still not removed. This may, however, vary between years and also islands, and it is a wellknown fact that American mink can occur frequently in the Baltic sea and do a lot of damage (Nordström et al. 2003; Bonesi and Palazon 2007).

In our study area, in the northernmost archipelago of the Baltic sea, where the raccoon dog is scarce and has a patchy distribution, it is desirable to set up a large scale long-term study of predation on natural nests. Such a study, although challenging, is necessary to determine if the current management is efficient enough to control the raccoon dog population down to a level where it will only cause acceptable damage (Courchamp et al. 2003). Based on our data, we do not doubt that some nesting islands fail completely each year, due to raccoon dogs finding them and causing detrimental effects on the birds' nesting success. Some of these nests may well be of threatened bird species, which would have made it had it not been for the raccoon dog. In more southern archipelagos where the raccoon dog densities are much higher, potentially causing even more damage, similar empirical studies, such as ours, are still surprisingly scarce. Väänänen et al. (2007), however, found a positive effect on the breeding success of waterbirds when reducing raccoon dog density in wetlands, and Ekroos et al. (2012) reported that raccoon dogs caused a $20 \%$ mortality on female eiders nesting on forested islands in the archipelago. Such findings, although still few, corroborate the conclusions of our study, that the raccoon dog may have a much larger effect on the breeding success of ground nesting bird species, at least in the archipelagos of northern Europe, than what has so far been the predominating view in the scientific literature (Kauhala and Kowalczyk 2011).

Acknowledgements Funding for the study and exemption for releasing raccoon dogs for the nest predation study (NV-0338316, NV-03794-15) was kindly provided by the Swedish Environmental Protection Agency (SEPA). According to the Swedish species protection regulation it is prohibited to intentionally disturb wild birds during the breeding season as well as to destroy or gather eggs (Artskyddsförordningen, 2007:845). We thank the county administrative board of Norrbotten for giving us an exemption from this regulation, which allowed us to use suitable islands outside protected areas for the experiment (D.nr. 522-7213-2016, 522-10291-2017). We acknowledge the work done on gathering the data by the involved field personnel. We are grateful for access to map data given by Lantmäteriet. The study was approved by the Swedish Ethics Committee on Animal Research (Dnr A18-16).

Open Access This article is distributed under the terms of the Creative Commons Attribution 4.0 International License (http:// creativecommons.org/licenses/by/4.0/), which permits unrestricted use, distribution, and reproduction in any medium, provided you give appropriate credit to the original author(s) and the source, provide a link to the Creative Commons license, and indicate if changes were made.

\section{References}

Anderson CJ, Hostetler ME, Sieving KE, Johnson SA (2016) Predation of artificial nests by introduced rhesus macaques (Macaca mulatta) in Florida, USA. Biol Invasions 18:2783-2789

Ankre R, Nilsson P (2006) The Luleå Archipelago, Sweden. In: Extreme tourism: lessons from the world's cold water islands. Elsevier (Advances in tourism research), pp 145-147

Bartmann B, White GC, Carpenter LH (1992) Compensatory mortality in a Colorado mule deer population. Wildl Monogr 121:1-39

Bonesi L, Palazon S (2007) The American mink in Europe; status, impacts, and control. Biol Conserv 134:470-483

Bottenvikens skärgård (2016). http://swedishlapland.nu/se/ Bottenvikens-skargard/info/Information/. Accessed 18 Oct 2016

Boyce MS, Sinclair ARE, White GC (1999) Seasonal compensation of predation and harvesting. Oikos 87:419-426

Courchamp F, Chapuis JL, Pascal M (2003) Mammal invaders on islands: impact, control and control impact. Biol Rev Camb Philos Soc 78:347-383

Dahl F, Åhlén PA, Granström ^ (2010) The management of raccoon dogs (Nyctereutes procyonoides) in Scandinavia. Aliens 30:59-63

DeCesare NJ, Hebblewhite M, Robinson HS, Musiani M (2010) Endangered, apparently: the role of apparent competition in endangered species conservation. Anim Conserv 13:353-362

Dettki H, Ericsson G, Giles T, Norrsken-Ericsson M (2013) Wireless remote animal monitoring (WRAM) - a new international database e-infrastructure for telemetry sensor data from fish and wildlife. In: The European Society of Telemetry (eds) Proceedings etc. 2012: convention for telemetry, test instrumentation and telecontrol, pp 247-256. ISBN: 978-3-7322-5646-4

Doherty TS, Glen AS, Nimmo DG, Ritchie EG, Dickman CR (2016) Invasive predators and global biodiversity loss. PNAS 113:11261-11265

Ebenhard T (1988) Introduced birds and mammals and their ecological effects. Swed Wildl Res 13:1-107

EC (2017) Commission Implementing Regulation (EU) 2017/1263 of 12 July 2017 updating the list of invasive alien species of Union concern established by Implementing Regulation (EU) 2016/1141 pursuant to 
Regulation (EU) No 1143/2014 of the European Parliament and of the Council. Off J Eur Union 182:37-40

Ehrenfeld JG (2011) Ecosystem consequences of biological invasions. Annu Rev Ecol Evol Syst 41:59-80

Ekroos J, Öst M, Karell P, Jaatinen K, Kilpi M (2012) Philopatric predisposition to predation-induced ecological traps: habitat-dependent mortality of breeding eiders. Oecologia 170:979-986

Elmeros M, Malene Götz Mikkelsen D, Nørgaard L, Pertoldi C, Jensen T, Chriél M (2018) The diet of feral raccoon dog (Nyctereutes procyonoides) and native badger (Meles meles) and red fox (Vulpes vulpes) in Denmark. Mamm Res. https://doi.org/10.1007/s13364-018-0372-2

Finnish Meteorological Institute (2018). http://en. ilmatieteenlaitos.fi/maps-from-1961-onwards. Accessed 29 Jan 2018

Heisey DM, Patterson BR (2006) A review of methods to estimate cause-specific mortality in presence of competing risks. J Wildl Manag 70:1544-1555

Helle E, Kauhala K (1991) Distribution history and present status of the raccoon dog in Finland. Holarct Ecol 14:278-286

Helle E, Kauhala K (1995) Reproduction of the raccoon dog in Finland. J Mamm 76:1036-1046

Herfindal I, Melis C, Åhlén PA, Dahl F (2016) Lack of sexspecific movement patterns in an alien species at its invasion front-consequences for invasion speed. Ecol Evol 6:5570-5584. https://doi.org/10.1002/ece3.2300

Holt RD (1977) Predation, apparent competition, and the structure of prey communities. Theor Popul Biol 12:197-229

Jahren T (2017) The role of nest predation and nest predators in population declines of capercaillie and black grouse. Doctoral thesis, Faculty of Applied Ecology and Agricultural Sciences, Inland Norway University of Applied Sciences, Norway

Kauhala K (1992) Ecological characteristics of the raccoon dog in Finland. Doctoral thesis, University of Helsinki, Helsinki, Finland

Kauhala K (2004) Removal of medium-sized predators and the breeding success of ducks in Finland. Folia Zool 53:367-378

Kauhala K, Auniola M (2001) Diet of raccoon dogs in summer in the Finnish archipelago. Ecography 24:151-156

Kauhala K, Kowalczyk R (2011) Invasion of the raccoon dog Nyctereutes procyonoides in Europe: history of colonization, features behind its success, and threats to native fauna. Curr Zool 57:584-598

Kauhala K, Laukkanen P, von Rége I (1998) Summer food composition and food niche overlap of the raccoon dog, red fox and badger in Finland. Ecography 21:457-463

Kauhala K, Schregel J, Auttila M (2010) Habitat impact on raccoon dog Nyctereutes procyonoides home range size in southern Finland. Acta Theriol 55:371-380

Kowalczyk R (2014) NOBANIS-invasive alien species fact sheet-Nyctereutes procyonoides. Online Database of the European Network on Invasive Alien Species-NOBANIS. www.nobanis.org. Accessed 29 Jan 2018
Länsstyrelsen (2009) Norrbottens kustfågelbestånd-inventering 2007 och 2008. Länsstyrelsens rapportserie 5-2009. Länsstyrelsen Norrbotten, Luleå, Sweden

Mack RN, Simberloff D, Lonsdale WM, Evans H, Clout M, Bazzaz FA (2000) Biotic invasions: causes, epidemiology, global consequences, and control. Ecol Appl 10:689-710. https://doi.org/10.1890/1051-0761(2000)010\%5b0689: BICEGC\%5d2.0.CO;2

McNeely JA, Mooney HA, Neville LE, Schei P, Waage JK (eds) (2001) A global strategy on invasive alien species. IUCN, Gland

Melis C, Herfindal I, Dahl F, Åhlén PA (2015) Individual and temporal variation in habitat association of an alien carnivore at its invasion front. PLoS ONE 10:3. https://doi. org/10.1371/journal.pone.0122492

MIRDINEC (2014) Management of the invasive Raccoon Dog (Nyctereutes procyonoides) in the north-European countries. LIFE09NAT/SE/000344. http://ec.europa.eu/ environment/life/bestprojects/bestnat2014/index.htm. Accessed 29 Jan 2018

Nogales M, Vidal E, Medina FM, Bonnaud E, Tershy BR, Campbell KJ, Zavaleta ES (2013) Feral cats and biodiversity conservation: the urgent prioritization of island management. BioScience 63:804-810. https://doi.org/10. 1525/bio.2013.63.10.7

Nordström M, Högmander J, Laine J, Nummelin J, Laanetu N, Korpimäki E (2003) Effects of feral mink removal on seabirds, waders and passerines on small islands in the Baltic Sea. Biol Conserv 109:359-368

Pejchar L, Mooney HA (2009) Invasive species, ecosystem services and human well-being. Trends Ecol Evol 24:497-504

Pollock KH, Winterstein SR, Bunck CM, Curtis PD (1989) Survival analysis in telemetry studies: the staggered entry design. J Wildl Manag 53:7-15

Sieving KE, Willson MF (1998) Nest predation and avian species diversity in northwestern forest understory. Ecology 79(7):2391-2402

SMHI (2016) Klimatindikator-temperatur. http://www.smhi. se/kunskapsbanken/klimat/klimatindikator-temperatur-1. 2430. Accessed 29 Jan 2018

Sutor A, Kauhala K, Ansorge H (2010) Diet of the raccoon dog Nyctereutes procyonoides: a canid with an opportunistic foraging strategy. Acta Theriol 55:165-176

Väänänen VM, Nummi P, Rautiainen A, Asanti T, Huolman I, Mikkola-Roos M, Nurmi J, Orava R, Rusanen P (2007) The effect of raccoon dog Nyctereutes procyonoides removal on waterbird breeding success. Suom Riista 53:49-63

Viro P, Mikkola H (1981) Food composition of the raccoon dog Nyctereutes procyonoides Gray, 1834 in Finland. Zeitschrift für Säugetierkunde 46:20-26

Weidema IR (2000) Introduced species in the Nordic countries. The Nordic Council of Ministers, Nord 2000:13, Copenhagen

Willebrand T, Marcstrom V (1988) On the danger of using dummy nests to study predation. Auk 105:378-379

Zanette L (2002) What do artificial nests tells us about nest predation? Biol Conserv 103:323-329 